\title{
Social Support and Acceptance Commitment Therapy on Subjective Well-Being and Mental Health of COVID-19 Patient
}

\author{
Imamatul Faizah ${ }^{1 *}$ (D), Yanis Kartini ${ }^{1} \mathbb{D}$, Ratna Yunita Sari ${ }^{1}$, Riska Rohmawati ${ }^{1}$, Raden Khairiyatul Afiyah ${ }^{1}$, \\ Firman Suryadi Rahman ${ }^{2}$ i \\ ${ }^{1}$ Departement of Nursing, Faculty of Nursing and Midwifery, Universitas Nahdlatul Ulama Surabaya, Surabaya, Indonesia; \\ ${ }^{2}$ Departement of Public Health, Faculty of Public Health, Universitas Airlangga, Surabaya, Indonesia
}

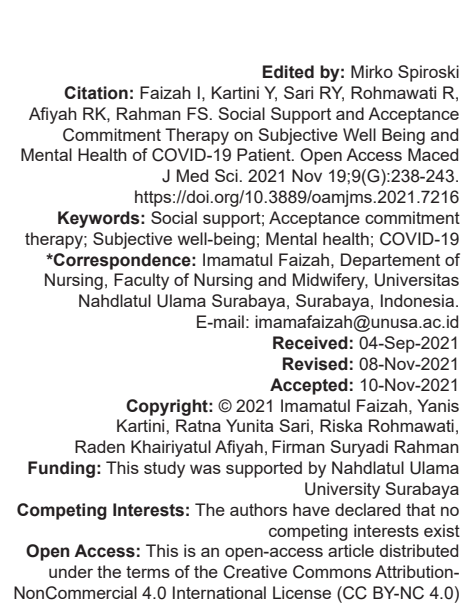

\section{Introduction}

COVID-19 is an infectious disease caused by severe acute respiratory syndrome coronavirus 2 (SARS-CoV-2), a global pandemic. Transmission of this virus is through droplets that occur very quickly [1]. Currently, information regarding the number of COVID-19 viruses is still increasing regarding transmission, incubation period, symptoms, and quality of life of patients worldwide [2]. This long-lasting pandemic condition can have an impact on mental health problems for people who are positive for COVID-19. Patients with COVID-19 are very vulnerable to psychological impacts due to self-isolation at home or while undergoing treatment in a hospital for approximately 2 weeks to avoid physical contact with other people [3]. The psychological impact felt by COVID-19 sufferers can be in the form of stress, anxiety, and depression when ostracized by their social environment [4]. COVID-19 sufferers feel anxious about their illness and there is a stigma in society that they must stay away from COVID-19 patients and their families so that patients feel excluded [5]. Negative feelings from within the patient will decrease the patient's subjective well-being or happiness and interfere with the patient's mental health [6].

The results of the mental health survey when the PDSKI swab was conducted online, explained that $63 \%$ of respondents experienced anxiety, and $66 \%$ of respondents experienced depression due to the COVID-19 pandemic. Research by Zhang et al. [7] showed that patients suffering from COVID-19 experienced a $29.2 \%$ increase in the incidence of depression after undergoing self-isolation. In July 2020, a COVID-19 patient in Surabaya, East Java, suicided by jumped from the $6^{\text {th }}$ floor of the hospital due to depression because his swab results were tested positive 7 times. This case explains that the psychological problems in COVID-19 patients need to be addressed immediately. The results of the COVID-19 Report survey show $53.6 \%$ of 
survivor respondents said they only involved their partners when they were first tested positive for COVID-19. Next are parents (21\%) and friends/coworkers (10.5\%).

The support given to COVID-19 sufferers is very meaningful. The same survey report that $70.2 \%$ of survivor respondents said they needed support by asking how they were doing [8]. Efforts to support mental health and subjective well-being for COVID-19 patients and survivors and their families can be conducted through the provision of social support. Social support from family, friends, and medical personnel can help patients to meet their psychological needs. The research conducted by El-Zoghby et al. [9] discovered that the provision of social support from family $(64.7 \%)$ can improve mental health during the COVID-19 pandemic. Meanwhile, research conducted by Yang et al. revealed that there is a positive relationship between peer social support and subjective well-being $(r=0.285, p=0.001)$, and there is a positive and significant relationship between family function and peer social support with subjective wellbeing $p=0.000$ or $p<0.05$ and $F=9.456>F$ table 3.04 This study added a new variant that family functioning and peer social support can predict subjective well-being by $8.3 \%$. Providing social support can create feelings of happiness and make patients think clearly to minimize mental health disorders in patients [10].

The research of $\mathrm{Xu}$ et al. [11] obtained results for susceptible, symptomatic but contented, depressed individuals. Before the intervention, there was no significant difference between the intervention group and the control group in terms of psychological distress, well-being, and psychological flexibility $(p>0.05)$. After the intervention, psychological distress and avoidance experience were significantly lower in the intervention group than in the control group. However, all dimensions of well-being were significantly higher in the intervention group than in the control group ( $p<0.05$ ). For susceptible, symptomatic but satisfied and depressed individuals, before and after the intervention, there were significant differences in psychological distress, well-being, and psychological flexibility from the intervention group ( $p<0.05)$, but no significant differences in the control group ( $p>0.05$ ). In this case, acceptance commitment therapy aims to provide a meaningful life by accepting the illness suffered by COVID-19 patients [12]. Management that can be used to improve subjective well-being and mental health of patients is to provide social support and acceptance commitment therapy that can be provided by the family or by medical personnel [13]. Giving acceptance commitment therapy can increase the patient's psychological flexibility in living their daily lives in accordance with their values and life goals [14]. Acceptance commitment therapy can be carried out as a preventive effort to improve mental health and improve subjective well-being of COVID-19 patients.

The purpose of this study was to determine the effect of social support and acceptance commitment therapy on subjective well-being and mental health of COVID-19 patients.

\section{Methods}

\section{General background of research}

This study used a quasi-experimental research design with the untreated control group design using dependent pre-test and post-test samples. This study involved two groups of subjects, namely the treatment group and the control group. The independent variables in this study were social support and acceptance commitment therapy. The dependent variable in this study is subjective well-being and mental health.

\section{Sample of research}

The population in this study were all positive COVID-19 patients at Surabaya Islamic Hospital who met the inclusion and exclusion criteria of the study. Sampling was done through consecutive sampling, in which the inclusion criteria are confirmed positive for COVID-19, composmentis awareness, vital signs within normal limits, while the exclusion criteria are the patient has decreased consciousness, communication disorders, and severe psychological disorders. Based on the criteria, the total respondents in this study were 106 respondents with 53 respondents in the intervention group and 53 respondents in the control group. In the intervention group, 27 were male and 26 were female, while in the control group 28 were male and 25 were female with an average age of 46-55 years in each group.

\section{Instrument and procedures}

The instrument used to measure the subjective well-being and mental health is an international standardized instrument. The measurement of subjective well-being was done by using the Satisfaction with Life Scale (SWSL) questionnaire. SWLS is an instrument composed by Ed Diener. This instrument is used to measure a person's life assessment of his life [15]. This instrument consists of 5 items with 7 rating scales consisting of (1) strongly dislike, (2) dislike, (3) slightly dislike, (4) moderate, (5) slightly like, (6) like, and (7) like it. Several studies reveal that these two instruments have high-reliability scores. SWLS has a reliability score of $0.82-0.87$ and the Indonesian translation of SWLS has a reliability of 0.733 .

Measurement of mental health using the Mental Health Inventory was developed by Veit and Jr (2015). The Mental Health Inventory includes 38 items in which the respondent uses a 6-point Likert-style response and it can generally be done without help. The test takes 
approximately $5-10 \mathrm{~min}$ to administer. There is an abbreviated version of the $\mathrm{MHI}$ which has only 5 items. This research used MHI 5 Items. According to the National Multiple Sclerosis Society, the Mental Health Inventory has a reported 0.93 Cronbach alpha rating whereas its abbreviated version has 0.82 . This test is well-known and has been field-tested in extensive populations. Also, the Mental Health Inventory showed a high correlation rating with MSQLI or Multiple Sclerosis Quality of Life Inventory.

This research was conducted in April-June 2021. Researchers first held a zoom meeting regarding the management and benefits of research with medical personnel and prospective respondents, then asked for informed consent from the respondents and distributed the questionnaires via Google form assisted by the COVID-19 isolation room nurse. The pre-test was carried out 1 day before the intervention was carried out. The researchers acted as therapists who were assisted by medical personnel as research assistants where the intervention group received social support and acceptance commitment therapy which was carried out every day for 2 weeks for \pm 30 min during the process of implementing Acceptance Commitment Therapy which was divided into 5 sessions. Session 1 is the discussion of problems and exercises for acceptance techniques by observing, breathing, and allowing. Session 2 is discussion of useless thoughts and exercises cognitive diffusion techniques by doing mind relaxation. Session 3 is mindfulness practice using awareness of breath and awareness of eating. Session 4 is discussion of three aspects of life that were considered important by participants and filled out a value assessment rating to find out priorities in the patient's life. Session 5 is practicing setting goals, review of the whole session, post-intervention assessment, and termination (Liang Z, 2021). The control group was not given any intervention, only to carry out the routines (habits) of each respondent. The post-test was carried out 1 day after the intervention. This research has been approved by the Ethics Committee of the Surabaya Islamic Hospital with the number 008.EC.KEP.RSIAY.05.21

\section{Data analysis}

The normality of the data was tested using Kolmogorov Smirnov and the data were normally distributed so that it was continued with data analysis using the Paired t-test for data before and after on subjective well-being and mental health. The post-test data of the intervention group and the control group were analyzed using the Independent t-test with a hypothesis of $p<0.05$.

\section{Results}

The characteristics of the participants in this study were based on age, gender, education, and occupation. The results of the characteristics of respondents in the study are as follows:

Table 1 shows that the characteristics of the research respondents obtained results that a small proportion in intervention and control group (24.5\% and $20.8 \%$ ) is in the early old age (46-55). For gender in both the intervention group and the control group, most of them are male $(50.9 \%$ and $52.8 \%)$. Based on the educational background in the intervention group, almost half $(45.3 \%)$ are Senior High School graduates, while in the control group, almost half (43.4\%) are Junior High School graduates. For occupation, almost half proportion in intervention and control group (35.8\% and $32.1 \%$ ) are Civil servant.

Table 1: Characteristics of respondents in the intervention group and control group

\begin{tabular}{|c|c|c|c|c|}
\hline \multirow[t]{2}{*}{ Characteristics } & \multicolumn{2}{|c|}{ Intervention group $(n=53)$} & \multicolumn{2}{|c|}{ Control group $(n=53)$} \\
\hline & $f$ & $\%$ & $f$ & $\%$ \\
\hline \multicolumn{5}{|l|}{ Age (Years) } \\
\hline Late teens $(17-25)$ & 7 & 13.2 & 4 & 7.5 \\
\hline Early adulthood (26-35) & 9 & 17.0 & 11 & 20.8 \\
\hline Late adulthood (36-45) & 6 & 11.3 & 9 & 17.0 \\
\hline Early old age (46-55) & 13 & 24.5 & 11 & 20.8 \\
\hline Late old age $(56-65)$ & 8 & 15.1 & 10 & 18.9 \\
\hline Old age $(>65)$ & 10 & 18.9 & 8 & 15.1 \\
\hline \multicolumn{5}{|l|}{ Sex } \\
\hline Male & 27 & 50.9 & 28 & 52.8 \\
\hline Female & 26 & 49.1 & 25 & 47.2 \\
\hline \multicolumn{5}{|l|}{ Education } \\
\hline Junior High School & 21 & 39.6 & 23 & 43.4 \\
\hline Senior High School & 24 & 45.3 & 19 & 35.8 \\
\hline University & 8 & 15.1 & 11 & 20.8 \\
\hline \multicolumn{5}{|l|}{ Occupation } \\
\hline Student & 7 & 13.2 & 4 & 7.5 \\
\hline Entrepreneur & 11 & 20.8 & 13 & 24.5 \\
\hline Civil servants & 19 & 35.8 & 17 & 32.1 \\
\hline Private employee & 4 & 7.5 & 4 & 7.5 \\
\hline Does not work & 12 & 22.6 & 15 & 28.3 \\
\hline
\end{tabular}

Table 2 the mean of mental health in the intervention group before the action was 34.21, while after the action, the mean of mental health was 73.92. For subjective well-being in the intervention group, before intervention was taken, an average of 10.06 was obtained and after intervention, the average value was 16.94, with $p=0.000$. It means there is a significant increase in mental health and subjective well-being before and after being given social support and acceptance commitment therapy. Meanwhile, in the control group, the mean of mental health in the intervention group before the action was 34.00 and after the intervention, the mean of mental health was 34.02. For subjective well-being in the intervention group, before the action was taken, an average of 9.70 was obtained and after intervention, the average value was 9.87 with $p=$ 0.0960 in mental health and 0.457 in subjective well-being, which means there was no significant increase in mental health and subjective well-being in the control group.

Table 2: Mental health and subjective well-being pre and post in the intervention and control group

\begin{tabular}{|c|c|c|c|c|c|c|c|c|c|}
\hline \multirow[t]{2}{*}{ Variable } & \multirow[t]{2}{*}{ Group } & \multicolumn{2}{|l|}{ Pre } & \multicolumn{2}{|l|}{ Post } & \multirow[t]{2}{*}{$95 \% \mathrm{Cl}$} & \multirow[t]{2}{*}{$t$} & \multirow[t]{2}{*}{$\mathrm{n}$} & \multirow[t]{2}{*}{$\mathrm{p}$-value } \\
\hline & & Mean & SD & Mean & SD & & & & \\
\hline \multirow{2}{*}{$\begin{array}{l}\text { Mental } \\
\text { Health }\end{array}$} & Intervention & 34.21 & 2.36 & 73.92 & 2.11 & $(-40.69)-$ & -81.9 & 53 & 0.000 \\
\hline & Control & 34.00 & 2.21 & 34.02 & 3.52 & $\begin{array}{l}(-38.75) \\
(-0.77)- \\
(-0.73)\end{array}$ & -0.05 & 53 & 0.960 \\
\hline \multirow[t]{2}{*}{$\begin{array}{l}\text { Subjective } \\
\text { Well-Being }\end{array}$} & Intervention & 10.06 & 2.30 & 16.94 & 2.09 & $\begin{array}{l}(-7.53)- \\
(-6.24)\end{array}$ & -21.3 & 53 & 0.000 \\
\hline & Control & 9.70 & 2.59 & 9.87 & 2.69 & $\begin{array}{l}(-0.62)- \\
(-0.28)\end{array}$ & -0.75 & 53 & 0.457 \\
\hline
\end{tabular}


Table 3 shows that based on the results of data analysis, the p-value of 0.000 was obtained on the mental health and subjective well-being after the intervention. Meanwhile, in the intervention group the difference in mean subjective well-being before and after the intervention was 6.88 , while the difference in the mean of mental health before and after the intervention was 39.71. In the control group, the difference in mean subjective well-being before and after the intervention was 0.17 , while the difference in the mean of mental health before and after the intervention was 0.02 .

\section{Discussion}

COVID-19 is an infectious disease caused by SARS-CoV-2, a global pandemic. Transmission of this virus is done through droplets that occur very quickly [1]. Currently, information regarding the number of COVID19 viruses is still increasing regarding transmission, incubation period, symptoms and quality of life of patients worldwide [16]. This long-lasting pandemic condition can have an impact on mental health problems for people who are positive for COVID-19. Patients with COVID19 are very vulnerable to psychological impacts due to self-isolation at home or while undergoing treatment in a hospital for approximately 2 weeks to avoid physical contact with other people. The psychological impact felt by COVID-19 sufferers can be in the form of stress, anxiety, and depression when ostracized by their social environment [4]. COVID-19 sufferers feel anxious about their illness and there is a stigma in society that they must stay away from COVID-19 patients and their families so that patients feel excluded [5]. Negative feelings within the patient will decrease the patient's subjective well-being or happiness and interfere with the patient's mental health [6].

Table 1 shows that a small proportion of the intervention and control groups (24.5\% and 20.8\%) were in the elderly (46-55). Previous studies linking the age factor with mortality divided age into two groups, namely age of below 50-years-old and age above 50 -years-old. The results show that the age group of above 50 years infected with COVID-19 had a higher risk of death than the age group below 50 years [17]. There is a relationship between age and the level of natural immunity, where elderly individuals are more likely to be infected and natural immunity decreases [18]. In addition, elderly individuals have consumed many drugs or consumed several types of drugs simultaneously to treat comorbidities that resulted in decreased organ function [19]. Recent studies explain that patients aged above 50 years can experience excessive ACE2 expression as a result of decreased immunity, decreased organ function, comorbidities and several other causes that increase the risk of death.

The results showed that most of them were male in the intervention group and the control group (50.9\% and $52.8 \%$ ). Based on a meta-analysis study linking gender with the risk of COVID-19 infection, it is known that men are $28 \%$ more at risk of infection than women. Compared to the relationship between sex and mortality, men are $1.86 \%$ more likely to die than women [17]. Men have higher ACE2 expression, and this is linked to sex hormones that put men at higher risk of contracting COVID-19. ACE2 expression is encoded by a gene found on the $X$ chromosome and females are heterozygous while males are homozygous, thus potentially increasing ACE2 expression. COVID-19 infection and some other clinical symptoms can be neutralized because women carry a heterozygous $X$ label called sexual dimorphism [20].

Positive swab results cause psychological reactions such as denial or rejection of the condition, anger or anger, bargaining or bargaining for the situation that will occur, depression, and acceptance [21]. Acceptance Commitment Therapy (ACT) is a psychological intervention using acceptance and mindfulness strategies that use behavior change and commitment strategies to increase psychological flexibility [14]. Acceptance Commitment Therapy serves to increase a person's psychological flexibility with the values that exist within him so that he can create a meaningful life [22].

Implementation of Acceptance Commitment Therapy is divided into five sessions. Session one is discussing problems and practicing acceptance techniques by observing, breathing, and letting. Session 2 is discussion useless thoughts and practiced cognitive diffusion techniques by doing mind relaxation. Session three is mindfulness exercises using breath awareness and eating awareness. Session 4 is discussing three aspects of life that were considered important by participants and filled out a value assessment to determine priorities in the patient's life. Session 5 is practice setting goals, reviewing the entire session, post-intervention assessment and termination [23].

The results of the study in Table 3 show that the average mental health in the intervention group is

Table 3: The value of the difference in mental health subjective well-being pre and post in the intervention group and the control group

\begin{tabular}{|c|c|c|c|c|c|c|c|c|c|c|}
\hline \multirow[t]{2}{*}{ Variable } & \multirow[t]{2}{*}{ Group } & \multirow[t]{2}{*}{ Mean } & \multirow[t]{2}{*}{ SD } & \multirow[t]{2}{*}{ SE } & \multirow[t]{2}{*}{$\mathrm{n}$} & \multirow[t]{2}{*}{ Mean Difference } & \multirow[t]{2}{*}{$\mathrm{t}$} & \multirow[t]{2}{*}{$95 \% \mathrm{Cl}$} & \multicolumn{2}{|c|}{$p$-value } \\
\hline & & & & & & & & & Pre & Post \\
\hline \multirow[t]{2}{*}{ Mental Health } & Intervention & 73.92 & 2.11 & 0.29 & 53 & 39.71 & 70.84 & $(38.78)-(41.03)$ & 0.335 & 0.000 \\
\hline & Control & 34.02 & 3.52 & 0.48 & 53 & 0.02 & & & & \\
\hline \multirow[t]{2}{*}{ Subjective Well-Being } & Intervention & 16.94 & 2.09 & 0.29 & 53 & 6.88 & 15.13 & $(6.15)-(8.00)$ & 0.753 & 0.000 \\
\hline & Control & 9.87 & 2.69 & 0.37 & 53 & 0.17 & & & & \\
\hline
\end{tabular}


39.71 , and the average difference in subjective wellbeing in the intervention group is 6.88 . This is based on the research results of Xiao et al. [24] on 1,472 health workers in Jiangsu Province, China, state that social support affects the mental health of health workers in dealing with the COVID-19 pandemic. Social support can be obtained from family members, superiors, and coworkers who are external sources that help in overcoming and overcoming a problem. The forms of social support during the current COVID-19 pandemic are (1) assessment support to solve problems or describe stressors, one of which is being a good listener, (2) real support, in the form of real assistance in solving problems, the assistance can be in the form of food, masks or medical equipment needed, (3) self-esteem support, support for a good self-view about oneself, in the form of economic assistance and mental support, and (4) support for a sense of belonging in the form of acceptance in one part or one group, in the form of social service not isolation for COVID-19 patients and medical personnel who treat COVID-19 patients [25].

Social support in dealing with the current coronavirus pandemic situation is very important in the human health dimension. Social support comes from close family, friends, co-workers, neighbors and friends in their activities. Social contact is very important for physical and mental health. Research shows that social contact and support can help reduce stress, depression, anxiety, isolation, self-esteem, normal life, well-being, and quality of life. In contrast, lack of social support has the opposite effect. The positive effect of good social support can be explained that this support has a direct impact on health and well-being because it provides comfort, a sense of purpose in life, and a sense of security. Social support can reduce various forms of stress, improve coping mechanisms and improve quality of life [26].

The implementation of Acceptance Commitment Therapy is divided into five sessions. Session one is discussing problems and practicing acceptance techniques by observing, breathing, and letting. Session 2 is discussing useless thoughts and practiced cognitive diffusion techniques by doing mind relaxation. Session three is mindfulness exercises using breath awareness and eating awareness. Session 4 is discussing three aspects of life that were considered important by participants and filled out a value assessment to determine priorities in the patient's life. Session 5 is practice setting goals, reviewing the entire session, post-intervention assessment and termination [23].

\section{Limitations}

Respondents are COVID-19 patients, thus limiting the movement of researchers and the team in data collection and intervention which was divided into several sessions, making respondents tired and bored.

\section{Implications}

Nurses as care service providers and health education providers are responsible for the health and mental well-being of COVID-19 patients.

Suggestions for further researchers:

1. Adding the population

2. Expanding the research area

3. Combining ACT with other interventions.

\section{Conclusion}

Regularly providing social support and commitment therapy can improve mental health and subjective well-being in COVID-19 patients. Improving Mental Health and Subjective Well-Being of COVID-19 sufferers can have a positive impact on patients. The provision of social support and acceptance commitment therapy can be carried out as a preventive effort to maintain mental health and subjective well-being of COVID-19 patients during the treatment period, both in hospital and self-isolation at home. The role of a nurse as care service providers and health education providers are responsible for the health and mental well-being of COVID-19 patients. Suggestions for further researchers is Adding the population, Expanding the research area and Combining ACT with other interventions.

\section{Acknowledgments}

We would like to thank all COVID-19 patients at Surabaya Islamic Hospital who are willing to be research respondents and medical personnel in the isolation room of Surabaya Islamic Hospital who have collaborated with researchers during data collection and the research process. Acknowledgments are expressed to Nahdlatul Ulama University Surabaya in terms of research funding and motivation in research.

\section{References}

1. Cui J, Li F, Shi ZL. Origin and evolution of pathogenic coronaviruses. Nat Rev Microbiol. 2019;17(3):181-92. http://doi. org/10.1038/s41579-018-0118-9

PMid:30531947

2. Mukhtar S. Psychological health during the coronavirus disease 2019 pandemic outbreak. Int J Soc Psychiatry. 2020;66(5):512-6. http://doi.org/10.1177/0020764020925835

PMid:32434402

3. Isbaniah F, Saputro DD, Sitompul PA, Susilo A, Wihastuti R, 
Manalu R. Pedoman Pencegahan dan Pengendalian Corona Virus Disease (Covid-19). Jakarta: Kementerian Kesehatan Rl; 2020.

4. Otu A, Charles $\mathrm{CH}$, Yaya S. Mental health and psychosocial well-being during the COVID-19 pandemic: The invisible elephant in the room. Int J Ment Health Syst. 2020;14:38. http://doi.org/10.1186/s13033-020-00371-w

PMid:32514302

5. Betty P, Carol SN. Mental health and the Covid-19 pandemic. N Engl J Med. 2020;14:38. http://doi.org/10.1186/ s13033-020-00371-w

PMid:32514302

6. Liang Z, Luo H, Liu C. The concept of subjective well-being: Its origins an application in tourism research: A critical review with reference to China. Tour Crit. 2021:2(2);2-12.

7. Zhang J, Lu H, Zeng $\mathrm{H}$, Zhang $\mathrm{S}$, Du Q, Jiang $\mathrm{T}$, et al. The differential psychological distress of populations affected by the COVID-19 pandemic. Brain Behav Immunity. 2020;87:49-50. http://doi.org/10.1016/j.bbi.2020.04.031

PMid:32304883

8. Kakemam E, Ghoddoosi-Nejad D, Chegini Z, Momeni K, Salehiniya $\mathrm{H}$, Hassanipour $\mathrm{S}$, et al. Knowledge, attitudes, and practices among the general population during COVID-19 outbreak in Iran: A national cross-sectional online survey. Front Public Health. 2020;8:585302. http://doi.org/10.3389/ fpubh.2020.585302

PMid:33363083

9. El-Zoghby SM, Enayat EM, Hend MS. Impact of the COVID19 pandemic on mental health and social support among adult Egyptians. J Community Health. 2020;45(4):689-95. http://doi. org/10.1007/s10900-020-00853-5

\section{PMid:32468155}

10. Yang $X$, Yang $X$, Kumar $P$, Cao B, Ma X, Li T. Social support and clinical improvement in COVID-19 positive patients in China. Nurs Outlook. 2020;68(6):830-7. http://doi.org/10.1016/j. outlook.2020.08.008 PMid:32980152

11. $\mathrm{Xu} X \mathrm{XW}, \mathrm{Wu} \mathrm{XX}$, Jiang $\mathrm{XG}, \mathrm{Xu} \mathrm{KJ}$, Ying $\mathrm{LJ}$, Ma $\mathrm{CL}$, et al. Clinical findings in a group of patients infected with the 2019 novel coronavirus (SARS-Cov-2) outside of Wuhan, China: Retrospective case series. BMJ. 2020;2020:368.

12. Stone AA, Mackie CE. Subjective Well-being: Measuring Happiness, Suffering, and other Dimensions of Experience. Washington, DC: National Academies Press; 2013.

13. Spoorthy MS, Pratapa SK, Mahant S. Mental health problems faced by healthcare workers due to the COVID-19 pandemic a review. Asian J Psychiatry. 2020;51:102119. http://doi. org/10.1016/j.ajp.2020.102119

PMid:32339895

14. Hayes SC, Luoma JB, Bond FW, Masuda A, Lillis J. Behaviour research and therapy. Behav Res Ther. 2006;44(1):1-25. http://doi.org/10.1016/j.brat.2005.06.006

PMid:16300724

15. Larsen RJ, Eid M. Ed Diener and the science of subjective wellbeing. In: The Science of Subjective Well-Being. New York, The Guilford Press; 2008. p. 1-3.
16. Corman VM, Landt $\mathrm{O}$, Kaiser M, Molenkamp R, Meijer A, Chu DK, et al. Detection of 2019 novel coronavirus (2019-nCoV) by real-time RT-PCR. Eurosurveillance. 2020;25(3):2000045. http://doi.org/10.2807/1560-7917.ES.2020.25.3.2000045 PMid:31992387

17. Biswas M, Rahaman S, Biswas TK, Haque Z, Ibrahim B. Association of sex, age, and comorbidities with mortality in COVID-19 patients: A systematic review and meta-analysis. Intervirology. 2021;64(1):36-47.

18. Luan J, Lu Y, Jin X, Zhang L. Spike protein recognition of mammalian ACE2 predicts the host range and an optimized ACE2 for SARS-CoV-2 infection. Biochem Biophys Res Commun. 2020;526(1):165-9. http://doi.org/10.1016/j. bbrc.2020.03.047

PMid:32201080

19. Huang C, Wang Y, Li X, Ren L, Zhao J, Hu Y, et al. Clinical features of patients infected with 2019 novel coronavirus in Wuhan, China. Lancet. 2020;395(10223):497-506. http://doi. org/10.1016/S0140-6736(20)30183-5 PMid:31986264

20. Gemmati D, Bramanti B, Serino ML, Secchiero P, Zauli G, Tisato V. COVID-19 and individual genetic susceptibility/ receptivity: Role of ACE1/ACE2 genes, immunity, inflammation and coagulation. Might the double X-chromosome in females be protective against SARS-CoV-2 compared to the single X-chromosome in males? Int J Mol Sci. 2020;21(10):3474. https://doi.org/10.3390/ijms21103474

PMid:32423094

21. Thirunavurakasu M, Thirunavukarasu P, Bhugra D. Concepts of mental health: Definitions and challenges. Int J Soc Psychiatry. 2013;59(3):197-8. https://doi.org/10.1177/0020764011422006 PMid:21975848

22. Najvani BD, Neshatdoost HT, Abedi MR, Mokarian F. The effect of acceptance and commitment therapy on depression and psychological flexibility in women with breast cancer. Zahedan $\mathrm{J}$ Res Med Sci. 2015;17(4):e965.

23. Bai Z, Luo S, Zhang L, Wu S, Chi I. Acceptance and commitment therapy (ACT) to reduce depression: A systematic review and meta-analysis. J Affect Disord. 2020;260:728-37. https://doi. org/10.1016/j.jad.2019.09.040

PMid:31563072

24. Xiao H, Zhang Y, Kong D, Li S, Yang N. The effects of social support on sleep quality of medical staff treating patients with coronavirus disease 2019 (COVID-19) in January and February 2020 in China. Med Sci Monit. 2020;26:e923549. https://doi. org/10.12659/MSM.923549

PMid:32132521

25. Xiang YT, Yang Y, Li W, Zhang L, Zhang Q, Cheung T, et al. Timely mental health care for the 2019 novel coronavirus outbreak is urgently needed. Lancet Psychiatry. 2020;7(3):228-9. https:// doi.org/10.1016/S2215-0366(20)30046-8 PMid:32032543

26. Serafini G, Parmigiani B, Amerio A, Aguglia A, Sher L, Amore M. The psychological impact of COVID-19 on the mental health in the general population. QJM. 2020;113(8):531-7. https://doi. org/10.1093/qjmed/hcaa201

PMid:32569360 